CARPENTIERI-PÍPOLO, V.; TAKAHASHI, H.W.; ENDO, R.M.; PETEK, M.R.; SEIFERT, A.L. Correlações entre caracteres quantitativos em milho pipoca. Horticultura Brasileira, Brasília, v. 20, n. 4, p. 551-554, dezembro 2002.

\title{
Correlações entre caracteres quantitativos em milho pipoca
}

\author{
Valéria Carpentieri-Pípolo; Hideaki Wilson Takahashi; Romeu Munashi Endo; Marcos Rafael Petek; \\ Adilson Luiz Seifert ${ }^{2}$
}

UEL, C. Postal 6001, 86.051-990 Londrina-PR; E-mail pipolo@uel.br ${ }^{1}$ estudante do curso de Agronomia da UEL; ${ }^{2}$ Doutorando em Melhoramento Vegetal da UEL. Bolsista CAPES

\section{RESUMO}

Em um programa de melhoramento, o conhecimento da grandeza das associações entre caracteres de interesse, é de fundamental importância na obtenção de populações melhoradas. O presente trabalho teve como objetivo determinar as correlações genotípicas, fenotípicas e ambientais entre caracteres quantitativos em milho pipoca. Foram avaliados nove genótipos de milho pipoca dispostos no campo em delineamento em blocos casualizados com oito repetições. Os genótipos UEL ZP, UEL SI e UEL PAP revelaram maiores capacidades de expansão $(27,50 ; 27,15$ e 24,40 respectivamente) e número de grãos por volume $(244,75 ; 248,50$ e 248,75 respectivamente). A capacidade de expansão revelou correlação fenotípica positiva com o tamanho da pipoca e com o número de grãos por volume, e correlação negativa com massa de grãos por planta. Os caracteres massa de grãos por planta e peso total da espiga revelaram correlações fenotípicas e genotípicas positivas entre si, o que possibilita a utilização de um ou outro na seleção, optando-se pelo que melhor convier aos propósitos do programa de melhoramento.

Palavras-chave: Zea mays, milho pipoca, genótipos, capacidade de expansão.

\begin{abstract}
Correlation among quantitative traits in popcorn maize

Knowledge of the size of the association among traits of interest is of fundamental importance in a breeding program to allow genetic progress. The genotypic, phenotypic and environment correlation were studied among quantitative traits of popcorn maize. Nine popcorn maize genotypes were assessed. A randomized complete block design with eight replications was used. The UEL ZP, UEL SI and UEL PAP. genotypes which had greatest expansion capacity (27.50; 27.15 and 24.20 , respectively), also had the greatest values for the number of grains per volume $(244.75 ; 248.50$ and 248.75 , respectively). The expansion capacity correlated positively with the popcorn size and with number of grains per volume and negatively with plant yield. The traits plant yield, and total ear weight showed positive phenotypic and genotypic correlation that permits the choice of the trait that always suits at the breeding objectives.
\end{abstract}

Keywords: Zea mays, popcorn, genotypes, popping expansion.

\section{(Recebido para publicação em 5 de outubro de 2000 e aceito em 12 de setembro de 2002)}

$\mathrm{A}$ cultura do milho pipoca no Brasil, apesar da elevada expressão econômica carece de dados oficiais sobre área plantada, ou mesmo da produtividade de variedades nacionais em fase de melhoramento. De acordo com informações das empresas que atuam no setor, foram importadas, em 1998, cerca de 61 mil toneladas, e a produção nacional foi de aproximadamente $20 \mathrm{mil}$ toneladas, podendo-se estimar que o consumo atual esteja em torno de $80 \mathrm{mil}$ toneladas de grãos (Pacheco et al., 1998; Galvão et al., 2000; Pereira \& Amaral Júnior, 2001).

Ziegler \& Ashman (1994), comparando híbridos de milho pipoca com híbridos de milho normal, observaram que o milho pipoca possui maior tamanho de pendão e prolificidade; espigas menores, situadas numa posição mais alta; colmos mais finos e fracos, sendo mais suscetíveis ao acamamento; maior suscetibilidade a doenças e menor produtividade. Isto se deve ao fato de, em milho pipoca, os caracteres agronômicos serem considerados menos importantes que os caracteres de qualidade sofrendo, pois, menor pressão de seleção.

Estudos de herança realizados por Dofing et al. (1991) e Pereira \& Amaral Júnior (2001) demostraram que o principal componente de variação genética da capacidade de expansão (CE) foram os efeitos genéticos aditivos, sendo que, em alguns casos, contribuiram os efeitos de dominância, enquanto que os efeitos epistáticos não foram significativos. Resultados semelhantes foram relatados por Lyerly (1942) que observou, em cruzamentos entre linhagens de baixa e alta CE, a obtenção de híbridos com CE próxima da média, evidenciando a predominância de efeitos aditivos, embora, em alguns cruzamentos, tenham ocorrido efeitos de dominância e de sobredominância.

Estimativas elevadas de herdabilidade para capacidade de expansão foram observadas por Robbins \&
Ashman (1984) por meio da avaliação das gerações $F_{2}$ e $F_{3}$ originadas de cruzamentos de linhagens de milho pipoca com linhagens de milho dentado e milho flint. Os autores observaram que a recuperação da $\mathrm{CE}$ foi ligeiramente maior nas progênies originadas nos cruzamentos de milho flint, indicando que nem todos os genes que contribuem para dureza do endosperma afetam a CE da pipoca e que o milho dentado também pode ser usado como fonte de genes para o melhoramento de milho pipoca.

Ao avaliar o cruzamento entre diversas linhagens de milho pipoca com linhagens de milho dentado, Johnson \& Eldredge (1953) verificaram que a capacidade de expansão $(\mathrm{CE})$ pode ser recuperada com dois retrocruzamentos seguidos por seleção para $\mathrm{CE}$.

A eficiência da seleção de um caráter pode ser aumentada com a utilização de caracteres agronômicos correlacionados (Paterniani \& Campos, 1999). De acordo com Hallauer \& 
Tabela 1. Análise de variância de seis caracteres em nove genótipos de milho pipoca. Londrina, UEL, 1997/98.

\begin{tabular}{lclccccc}
\hline \multirow{2}{*}{ FV } & \multirow{2}{*}{ GL } & \multicolumn{7}{c}{ Quadrado Médio } \\
\cline { 3 - 8 } & & \multicolumn{1}{c}{ CE } & TP & NGV & CESP & MTE & MGP \\
\hline Blocos & 7 & 15,3868 & 0,9575 & 1064,3174 & 5,0510 & 228,8877 & 130,8671 \\
Genótipo & 8 & $83,6440^{* *}$ & 0,9308 & 2045,0625 & $12,0815^{* *}$ & $2170,9464^{* *}$ & $1433,4988^{* *}$ \\
Resíduo & 56 & 22,6748 & 0,8195 & 1340,6656 & 3,0042 & 256,5459 & 159,7304 \\
\hline CV & & 21,11 & 22,07 & 16,00 & 10,43 & 17,72 & 17,30 \\
\hline
\end{tabular}

** Significativo a 5\% de probabilidade pelo teste $\mathrm{F}$.

CE: capacidade de expansão $\left(\mathrm{cm}^{3}\right)$; TP: tamanho da pipoca $\left(\mathrm{cm}^{3}\right)$; NGV: número de grãos em $40 \mathrm{~cm}{ }^{3}$; CESP: comprimento da espiga (cm); MTE: massa total de espigas por planta (g) e MGP: massa de grãos por planta (g).

Miranda Filho (1988) a correlação estimada por meio do coeficiente de correlação tem importância no melhoramento de plantas, porque quantifica o grau de associação genético e não-genético entre dois ou mais caracteres. Também, Cruz \& Regazzi (1997) ressaltam a importância das correlações afirmando que essas associações quantificam a possibilidade de ganhos indiretos por seleção em caracteres correlacionados, e que caracteres de baixa herdabilidade têm a seleção mais eficiente quando realizada sobre caracteres que lhe são correlacionados.

O conhecimento da magnitude da natureza das associações entre caracteres de interesse no melhoramento de milho pipoca é de fundamental importância na obtenção de genótipos melhorados.

Este trabalho teve como objetivo estimar as correlações genotípicas, fenotípicas e ambientais entre seis caracteres em milho pipoca.

\section{MATERIAL E MÉTODOS}

Nove genótipos de milho pipoca, procedeNove genótipos de milho pipoca, procedentes de três gerações de seleção dentro de linhagens, híbridos simples e híbridos triplos comerciais de milho pipoca foram avaliados em um experimento instalado na UEL (PR). Os genótipos avaliados foram: UEL MP, UEL YY, UEL SI, UEL MPS, UEL BG, UEL PAG, UEL PAP, UEL ZP e UEL PP.

Utilizou-se o delineamento experimental em blocos casualizados com nove tratamentos e oito repetições. As parcelas foram constituídas de duas linhas de 5 metros de comprimento, densidade utilizada foi de 50.000 plantas por hectare. O solo da área experimental foi classificado como Latossolo Vermelho Escuro distrófico, com textura e fertilidade média. A adubação foi feita com $500 \mathrm{~kg} /$ ha da fórmula 8-28-16 no plantio, mais $100 \mathrm{~kg} /$ ha de uréia em cobertura aos 30 dias após a emergência.

Os caracteres avaliados foram: comprimento médio da espiga em $\mathrm{cm}$ (CESP), tomado a partir de uma amostra de 10 espigas por parcela; massa total das espigas despalhadas em gramas (MTE), média estimada a partir da massa total das espigas despalhadas por planta; massa de grãos por planta em gramas (MGP), determinada a partir da massa total de grãos por planta; rendimento de grãos em $\mathrm{Kg} /$ ha $(\mathrm{RG})$, estimada a partir da MGP, número de plantas por parcela e área da parcela; número de grãos em $40 \mathrm{~cm}^{3}(\mathrm{NGV})$, determinado a partir de uma amostra de grãos de $40 \mathrm{~cm}^{3}$ retirada da parte centro-basal de 10 espigas por parcela; capacidade de expansão (CE), obtido pela relação entre volume de pipoca estourada e o volume de grãos utilizados. A CE foi obtida de uma amostra de grãos de 40 $\mathrm{cm}^{3}$ retirada da parte centro-basal de 10 espigas por parcela. Após a uniformização da umidade (11\%), obteve-se a expansão dos grãos, utilizando um pipocador convencional (pipocador caseiro), e o volume da pipoca medido em uma proveta de $1000 \mathrm{~cm}^{3}$. Padronizouse o tempo do pipocamento em 48 segundos após a temperatura do interior do pipocador ter atingido $180^{\circ} \mathrm{C}$ em 2,5 $\mathrm{ml}$ de óleo vegetal por $40 \mathrm{~cm}^{3}$ de grãos. A temperatura no interior do pipocador foi medida com auxílio do aparelho Termopar (Radionave TDR 1000 - Indústrias Eletrônicas); o tamanho da pipoca (TP) foi obtido pela relação entre o volume da pipoca estourada e o nú- mero de grãos estourados $\left(\mathrm{cm}^{3}\right)$.

Foram realizadas as análises de variância para cada caráter e determinadas as estimativas dos parâmetros genéticos-estatistícos, empregando o método de Vencovsky (1987).

Os coeficientes de correlação fenotípica $\left(\mathrm{r}_{\mathrm{F}}\right)$, genotípica $\left(\mathrm{r}_{\mathrm{G}}\right)$ e ambiental $\left(\mathrm{r}_{\mathrm{A}}\right)$ foram calculados pelas seguintes expressões (Cruz \& Regazzi, 1997):

$$
\begin{aligned}
& r_{F}=\frac{\operatorname{COV}_{F(x, y)}}{\sqrt{\left(\sigma_{F x}^{2} \cdot \sigma_{F y}^{2}\right)}} \\
& r_{G}=\frac{\operatorname{COV}_{G(x, y)}}{\sqrt{\left(\sigma_{G x}^{2} \cdot \sigma_{G y}^{2}\right)}} \\
& r_{A}=\frac{\operatorname{COV}_{A(x, y)}}{\sqrt{\left(\sigma_{\left.A x \cdot \sigma_{A y}^{2}\right)}^{2}\right.}}
\end{aligned}
$$

, em que: $\operatorname{COV}_{\mathrm{F}(\mathrm{x}, \mathrm{y})}, \mathrm{COV}_{\mathrm{G}(\mathrm{x}, \mathrm{y})}$ e $\operatorname{COV}_{\mathrm{A}(\mathrm{x}, \mathrm{y})}$ correspondem, respectivamente, às covariâncias fenotípicas, genotípicas e ambientais entre os caracteres $\mathrm{x}$ e $\mathrm{y} ; \mathrm{s}^{2}{ }_{\mathrm{Fx}}$, $\mathrm{s}_{\mathrm{Gx}}^{2}, \mathrm{e} \mathrm{s}^{2}{ }_{\mathrm{Ax}}$ correspondem às variâncias fenotípica, genotípica e ambiental do caráter $\mathrm{x} ; \mathrm{s}_{\mathrm{Fy}}^{2}, \mathrm{~s}_{\mathrm{Gy}}^{2} \mathrm{e} \mathrm{s}^{2}{ }_{\mathrm{Ay}}$ correspondem, respectivamente às variâncias fenotípica, genotípica e ambiental do caráter y. A significância dos coeficientes de correlação fenotípica, genotípica e ambiental foi avaliada pelo teste $\mathrm{t}$, em $5 \%$ e $1 \%$ de significância (Steel \& Torrie, 1980).

\section{RESULTADOS E DISCUSSÃO}

Exceto para TP e NGV, a análise de variância revelou diferenças significativas pelo teste $\mathrm{F}$ em $5 \%$ de probabili- 
Correlações entre caracteres quantitativos em milho pipoca

Tabela 2. Comparação entre as médias de nove genótipos de milho pipoca em relação a sete caracteres avaliados. Londrina, UEL, $1997 / 98$.

\begin{tabular}{lllllrll}
\hline Genótipo & \multicolumn{1}{c}{ CE } & TP & NGV & CESP & MTE & MGP & \multicolumn{1}{c}{ RG } \\
\hline UEL ZP & $27,50 \mathrm{a}$ & 4,61 & 244,75 & $19,43 \mathrm{c}$ & $104,39 \mathrm{~b}$ & $82,55 \mathrm{~b}$ & $3302,00 \mathrm{~b}$ \\
UEL SI & $27,15 \mathrm{a}$ & 4,55 & 248,50 & $16,81 \mathrm{~b}$ & $83,59 \mathrm{~cd}$ & $65,92 \mathrm{~cd}$ & $2636,80 \mathrm{~cd}$ \\
UEL PAP & $24,40 \mathrm{ab}$ & 4,04 & 248,75 & $15,68 \mathrm{~b}$ & $81,81 \mathrm{~cd}$ & $66,83 \mathrm{~cd}$ & $2673,20 \mathrm{~cd}$ \\
UEL BG & $22,71 \mathrm{abc}$ & 4,20 & 225,62 & $16,00 \mathrm{~b}$ & $81,05 \mathrm{~cd}$ & $65,35 \mathrm{~cd}$ & $2614,00 \mathrm{~cd}$ \\
UEL PAG & $21,87 \mathrm{bc}$ & 4,09 & 230,25 & $15,87 \mathrm{~b}$ & $85,40 \mathrm{~cd}$ & $68,58 \mathrm{c}$ & $2743,20 \mathrm{c}$ \\
UEL MPS & $21,06 \mathrm{bc}$ & 4,16 & 215,62 & $16,93 \mathrm{~b}$ & $93,35 \mathrm{bc}$ & $75,84 \mathrm{bc}$ & $3033,60 \mathrm{bc}$ \\
UEL YY & $20,68 \mathrm{bc}$ & 3,90 & 218,87 & $15,18 \mathrm{~b}$ & $67,60 \mathrm{~d}$ & $54,49 \mathrm{~d}$ & $2179,60 \mathrm{~d}$ \\
UEL PP & $19,06 \mathrm{bc}$ & 3,54 & 224,87 & $17,00 \mathrm{~b}$ & $125,24 \mathrm{a}$ & $101,55 \mathrm{a}$ & $4062,00 \mathrm{a}$ \\
UEL MP & $18,53 \mathrm{c}$ & 3,77 & 202,25 & $16,62 \mathrm{~b}$ & $91,23 \mathrm{bc}$ & $76,21 \mathrm{bc}$ & $3048,40 \mathrm{bc}$ \\
\hline
\end{tabular}

CE: capacidade de expansão $\left(\mathrm{cm}^{3}\right)$; TP: tamanho da pipoca $\left(\mathrm{cm}^{3}\right)$; NGV: número de grãos em $40 \mathrm{~cm}^{3}$; CESP: comprimento da espiga (cm); MTE: massa total de espigas por planta (g); MGP: massa de grãos por planta (g); e RG: rendimento de grãos em kg/ha.

Médias seguidas da mesma letra, na coluna, não diferem entre si pelo teste de Duncan a $5 \%$ de probabilidade.

Tabela 3. Média, variância fenotípica $\left(\mathrm{O}_{\mathrm{F}}^{-2}\right)$, genotípica $\left(\mathrm{O}_{\mathrm{G}}^{-2}\right)$ e ambiental $\left(\mathrm{O}^{-2}\right)$ para seis caracteres quantitativos em milho pipoca. Londrina, UEL, 1997/98.

\begin{tabular}{lccrrrr}
\hline & CE & TP & NGV & CESP & MTE & \multicolumn{1}{c}{ MGP } \\
\hline Médias & 22,56 & 4,10 & 228,83 & 16,62 & 90,41 & 73,04 \\
$\mathrm{O}^{-2}{ }_{\mathrm{F}}$ & 10,45 & 0,12 & 255,63 & 1,51 & 271,36 & 179,18 \\
$\mathrm{O}^{-2}{ }_{G}$ & 7,72 & 0,02 & 91,88 & 1,10 & 239,68 & 159,62 \\
$\mathrm{O}^{-2}{ }_{\mathrm{A}}$ & 2,73 & 0,10 & 163,74 & 0,40 & 31,68 & 19,56 \\
\hline
\end{tabular}

CE: capacidade de expansão $\left(\mathrm{cm}^{3}\right)$; TP: tamanho da pipoca $\left(\mathrm{cm}^{3}\right)$; NGV: número de grãos em $40 \mathrm{~cm}^{3}$; CESP: comprimento da espiga (cm); MTE: massa total de espigas por planta (g); e MGP: massa de grãos por planta (g).

dade para as características avaliadas (Tabela 1). O coeficiente de variação experimental (CV) foi inferior a $25 \%$ para todos os caracteres avaliados, o que revela bom nível de precisão nos experimentos de campo. De fato, para caracteres quantitativos esperam-se magnitudes de $\mathrm{CV}$ próximas às obtidas, concordando com as encontradas na literatura, para milho pipoca.

Os genótipos UEL ZP e UEL SI, por apresentarem CE acima de $27,00 \mathrm{~cm}^{3} \mathrm{e}$ TP maior que $4,5 \mathrm{~cm}^{3}$, além de UEL PAP, que conteve $\mathrm{CE}=24,40 \mathrm{e} \mathrm{TP}=4,04(\mathrm{Ta}-$ bela 2), possuem características de qualidade exigidas pelo comércio (Gomes et al., 1990), sendo, pois, promissores para utilização pelos produtores ou para serem empregados em programas de melhoramento com a espécie.

Os genótipos UEL ZP, UEL SI e UEL PAP, nesta ordem, com maior CE, revelaram também valores para NGV $(244,75 ; 248,50$ e 248,75 , respectivamente) (Tabela 2). A CE do milho pipoca relaciona-se negativamente com o tamanho do grão; assim, a seleção indi- reta para CE pode ser realizada através da seleção de genótipos de grãos pequenos (Souza Júnior et al., 1985). Para fornecer uma análise mais completa, a Tabela 2 contém o rendimento de grãos dos genótipos, em kg/ha. Comparandose os genótipos, verifica-se que embora UEL PP tenha apresentado o maior valor para RG, UEL ZP revelou maior potencial seletivo, pois destacou-se dos demais, com valor de $\mathrm{CE}=27,50$ e $\mathrm{RG}$ acima de $3300 \mathrm{~kg} / \mathrm{ha}$.

Considerando-se que o número de variedades de milho pipoca no mercado brasileiro é pequeno e o melhoramento intrapopulacional é uma opção de desenvolvimento de novas variedades para uso 'per se' e para futuros trabalhos de extração de linhagens endogâmicas acredita-se que UEL ZP apresente maior potencial seletivo que os demais genótipos avaliados.

Os caracteres avaliados que apresentaram maiores variâncias fenotípicas foram MTE, NGV, MGP e CE. Exceto para NGV e TP, as variâncias genotípicas dos demais caracteres foram análogas às superiores fenotípicas (Tabela 3).

Pela Tabela 4, constata-se a ocorrência de correlação fenotípica positiva entre CE e NGV $(0,879)$, o que comprova os resultados da Tabela 2, na qual os genótipos com maior $\mathrm{CE}$ também apresentam maior NGV. Sendo assim, pode-se concluir que em programas de melhoramento com milho pipoca, o melhorista pode selecionar para $\mathrm{CE}$, com base em NGV, isto é, seleção de genótipos com maiores capacidades de expansão, com base nos que possuem grãos menores. De forma semelhante, o melhorista poderá fazer seleção indireta para CE através de TP, pois, a correlação entre essas características foi positiva e significativa $(0,909)$.

A CE apresentou correlação negativa com MTE $(-0,148)$. Estudos de correlação entre caracteres da planta, da espiga e do grão com a $\mathrm{CE}$ têm sido efetuados em diversas populações de milho pipoca. De modo geral, os caracteres de maior importância agronômica, como produção de grãos, peso 
Tabela 4. Estimativas dos coeficientes de correlação fenotípica (acima da diagonal), genotípica (acima da diagonal, entre parêntesis) e de ambiente (abaixo da diagonal), entre seis caracteres em milho pipoca. Londrina, UEL, 1997/98.

\begin{tabular}{lcccccc}
\hline & CE & TP & NGV & CESP & MTE & MGP \\
\hline CE & & $0,909^{*}$ & $0,879^{*}$ & 0,451 & $-0,148$ & $-0,223$ \\
& & $(0,880)^{*}$ & $(0,449)$ & $(0,600)$ & $(-0,164)$ & $(-0,265)$ \\
TP & & 0,629 & 0,476 & $-0,254$ & $-0,325$ \\
& $0,720^{*}$ & & $(0,429)$ & $(0,126)$ & $(-0,204)$ & $(-0,417)$ \\
NGV & & & 0,251 & $-0,015$ & $-0,084$ \\
& $0,362^{*}$ & $-0,354^{*}$ & & $(0,758)^{* *}$ & $(0,302)$ & $(0,155)$ \\
CESP & & & & & 0,633 & 0,590 \\
& 0,027 & $0,295^{* *}$ & $-0,334^{* *}$ & & $(0,638)$ & $(0,590)$ \\
MTE & & & & & & $0,995^{*}$ \\
& $-0,090$ & $0,425^{*}$ & $-0,651^{*}$ & $0,662^{*}$ & & $(0,997)^{*}$ \\
MGP & & & & & & \\
\hline
\end{tabular}

CE: capacidade de expansão $\left(\mathrm{cm}^{3}\right)$; TP: tamanho da pipoca $\left(\mathrm{cm}^{3}\right)$; NGV: número de grãos em $40 \mathrm{~cm}^{3}$; CESP: comprimento da espiga (cm); MTE: massa total de espigas por planta (g); e MGP: massa de grãos por planta (g).

*; ** indica significância pelo teste $\mathrm{t}$ ao nível de $1 \%$ e $5 \%$ de probabilidade, respectivamente.

de 100 grãos, altura da planta, altura da espiga e tamanho do grão relacionam-se negativamente com CE. Apenas prolificidade e número de fileiras na espiga têm apresentado correlação positiva (Willier \& Brunson, 1967; Lyerly, 1942; Dofing et al., 1991; Lira, 1983; Sawazaki, 1996). Galvão et al. (2000) relataram relação direta entre prolificidade e produtividade, com magnitude de correlação de 0,65 para esses caracteres. $\mathrm{O}$ aumento da produtividade por meio do aumento do número de espigas é, pois, uma opção para se conseguir ganhos de produtividade no milho pipoca sem que ocorra perda de qualidade dos grãos, uma vez que há correlação negativa entre produtividade e qualidade da pipoca.

Na Tabela 4 os caracteres MGP e MTE, revelaram correlações fenotípicas e genotípicas positivas entre si, podendo, assim, ser realizada a seleção para rendimento da espiga através da seleção do caráter de maior ganho genético ou no que possuir maior facilidade de avaliação.

Os resultados negativos entre os coeficientes de correlação ambiental (Tabela 4), de MTE e MGP para com $\mathrm{CE}$ indicam que as condições ambientais, que favorecem os caracteres MTE e MGP, influenciam negativamente o caráter CE. De forma análoga as condições ambientais que favorecem NGV influenciam negativamente TP.

Os valores da correlação ambiental entre CE e CESP foram positivos e não significativos. Conforme verificado nesta pesquisa. Esses resultados são explicados porque em milho pipoca, a seleção continuada para aumento da capacidade de expansão produz modificações de caracteres correlacionados com produção de grãos.

\section{AGRADECIMENTOS}

Os autores agradecem ao $\mathrm{CNPq}$ e à CAPES pelo apoio financeiro, através da concessão das bolsas de estudo, durante a realização desta pesquisa.

\section{LITERATURA CITADA}

CRUZ, C.D.; REGAZZI, A.J. Modelos Biométricos Aplicados ao Melhoramento Genético. Viçosa: Editora da UFV, 1997. 390 p.

DOFING, S.M.; D`CROZ-MASON, N.; THOMAS-COMPTON, M.A. Inheritance of expansion volume and yield in two popcorn $\mathrm{x}$ dent corn crosses. Crop Science, v. 31, p. 715-718, 1991. GALVÃO, J.C.C.; SAWASAKI, E.; MIRANDA, G.V. Comportamento de híbridos de milho-pipoca em Coimbra, Minas Gerais. Revista Ceres, Viçosa, v. 47, p. 201-218, 2000.

GOMES, E.; GAMA, E.E.G.; MAGNAVACA, R.; SILVA, J.B.; SANS, L.M.A.; VIANA, P.A.; PARENTONI, S.N.; PACHECO, C.A.P.; CORREA, L.A.; FERNANDES, F.T. Milho Pipoca. Informe Agropecuário, Belo Horizonte, v. 14 , n. 165 , p. 8-12, 1990.

HALLAUER, A.R.; MIRANDA FILHO, J.B. Quantitative genetics in maize breeding. $2^{\text {nd }} \mathrm{ed}$. Iowa State University Press, Ames, Iowa, 1988. 468 p. JOHNSON, I.J.; ELDREDGE, J.C. Performance of recovered popcorn inbred lines derived from outcrosses to dent corn. Agronomy Journal, v. 45, p. $105-110,1953$.
LIRA, M.A. Seleção entre e dentro de famílias de meios irmãos para produção, capacidade de expansão e correlações entre alguns caracteres em milho pipoca (Zea mays L.). ESALQ, Lavras, MG., 1983. 63 p. (Tese mestrado)

LYERLY, P.J. Some genetic and morphological characters affecting the popping expansion of popcorn. Journal American Society of Agronomy, v. 34, p. 986-995, 1942.

PACHECO, C.A.P.; GAMA, E.E.G.; GUIMARÃES, P.E.D.; SANTOS, M.X.; FERREIRA, A.S. Estimativas de parâmetros genéticos nas populações CMS-42 e CMS-43 de milho pipoca. Pesquisa Agropecuária Brasileira, Brasília, v. 33, n. 12, p. 1995-2001, 1998.

PATERNIANI, E.; CAMPOS, M.S. Melhoramento do milho. In BORÉM, A. (Organizador). $\mathrm{Me}$ lhoramento de espécies cultivadas. Viçosa. Editora UFV, 1999. p. 429-485.

PEREIRA, M.G.; AMARAL JÚNIOR, A.T. Estimation of Genetic components in popcorn based on nested design. Crop Breeding and Applied Biotechnology, Londrina, v. 1, n. 1, p. 3-10, 2001. ROBBINS, W.A.; ASHMAN, R.B. Parentoffspring popping expansion correlation in progeny of dent x popcorn crosses. Crop Science, v. 24, p. 119-121, 1984.

SAWAZAKI, E. Parâmetros genéticos em milho pipoca. Piracicaba, ESALQ, 1996. 157 p. (Tese doutorado)

SOUZA JÚNIOR, C.L.; GERALDI, I.O.; ZINSLY, J.R. Influence of tassel size on the expression of prolificidacy in maize (Zea mays L.). Maydica, Bergamo, v. 30, p. 321-28, 1985. STEEL, R.G.D.; TORRIE, J.H. Principles and procedures of statistics: a biometrical approach. New York: McGraw - Hill Book Company, 1980. 633 p. VENCOVSKY, R. Herança quantitativa. In: PATERNIANI, E.; VIÉGAS, G.P. Melhoramento e produção de milho no Brasil. Campinas: Fundação Cargill, 1987. v. 5, p. 137-214.

WILLIER, J.B.; BRUNSON, A.M. Factor affecting the popping quality of popcorn (Zea mays L.). Crop Science, v. 7, p. 651-55, 1967.

ZIEGLER, K.E., ASHMAN, B. Popcorn. In: HALLAUER, A.R. (ed.) Specialty corns. Iowa, CRC Press, 1994. p. 189-223. 